\title{
SPACE, TRUST, AND COMMUNAL ACTION: RESULTS FROM FIELD EXPERIMENTS IN SOUTHEAST ASIA*
}

\author{
Jeffrey P. Carpenter \\ Department of Economics, Middlebury College, Middlebury, Vermont \\ and IZA, Bonn, Germany
}

\author{
Amrita G. Daniere \\ Department of Geography, University of Toronto, Mississauga, Canada. \\ E-mail: amrita.daniere@utoronto.ca \\ Lois M. Takahashi \\ Department of Urban Planning, University of California at Los Angeles, \\ Los Angeles, CA
}

\begin{abstract}
This paper examines the spatial dimensions of trust in two Southeast Asian cities using data from both household surveys and field experiments conducted in low-income communities. The results suggest that space and location are important to understanding communal action and trust in developing countries. Not surprisingly, space matters in different ways depending on culture, history and the political-economy of a particular country or city.
\end{abstract}

\section{INTRODUCTION}

The importance of trust to economic, political, and social development is widely acknowledged and, yet, not particularly well understood. At the same time, however, scholarship on trust and social capital takes as given that, as noted in The Economist (2003), "the more people trust each other, the better off their society." Research on trust and social capital suggests that trust is related to many positive social outcomes, such as economic growth (Whiteley, 2000), healthier communities (Kawachi, Kennedy, and Lochner, 1997), and

*The authors express their gratitude and appreciation to Dr. Anchana NaRanong at the National Institute for Development Administration in Bangkok, Thailand; Dr. Nguyen Quang Vinh and Ms. Van Thi Ngoc Lan of the Institute for Social Sciences in Ho Chi Minh City, without whom this research could not have been conducted. We also thank Molly Davidson-Welling, Nadia AbuZahra, and Jill Wigle of the Department of Geography at the University of Toronto for their substantial contributions. We are grateful to the University of California Pacific Rim Research Program, the Social Science and Humanities Research Council of Canada, and the National Science Foundation (CAREER 0092953) for funding this research. Finally, we would like to acknowledge the very helpful suggestions of Marlon Boarnet and two anonymous referees. We remain responsible for all errors and omissions.

Received: November 2004; Revised: July 2005; Accepted: September 2005.

(C) Blackwell Publishing, Inc. 2006.

Blackwell Publishing, Inc., 350 Main Street, Malden, MA 02148, USA and 9600 Garsington Road, Oxford, OX4 2DQ, UK. 
environmental management (Daniere, Takahashi, and NaRanong, 2002). In research on social capital, trust is singled out for attention because it underlies most non-market interactions (Glaeser et al., 2000; Paldam, 2000; Willinger et al., 2003; Carpenter, Daniere, and Takahashi, 2004a), it facilitates social and political interactions, and it improves the odds of success in cooperative ventures (Gambetta, 1988; Putnam, 1995; Freitag, 2004). Essentially, trust reinforces the willingness of people to act in the interest of the group or community, which, in turn, allows them to resolve social dilemmas together.

However, while researchers have carefully examined the social dimensions of trust, there has been much less attention paid to its spatial dimensions. To begin to address this gap, we explore the role of space and location on trust, using both survey data and the results of experimental games conducted in two large cities of Southeast Asia (Bangkok, Thailand and Ho Chi Minh City (HCMC), Vietnam). Specifically, we seek to answer the following question: How important is geography/spatial location in explaining variations in trust and the potential for communal action?

To answer this question, we begin with a review of scholarship on trust and the ways in which space and location might play a critical role. We then briefly overview the experimental economics method for measuring trust. We then present the several contexts and detail the methodologies we used to collect a unique data set in several urban communities in Southeast Asia. We then report our results and findings. We conclude with policy implications and directions for future research in the face of the enormous volume of work currently geared to assessing and evaluating trust and the positive and negative impacts it can have on society.

\section{SPATIALIZING TRUST AND SOCIAL OUTCOMES}

\section{Space, Trust, and Economy}

Geographers and regional scientists have taken the lead in exploring the spatial dimensions of social interaction, such as trust, and its influence on economic development (Thrift and Olds, 1996). The new economic geography has explored the role of social and cultural norms on varying economic sectors, such as manufacturing, finance, and tourism (Lloyd, 2003). Research on economic opportunities, in particular, has emphasized the key role played by networks of personal contact for the transmission of business information and knowledge (Amin and Thrift, 1995) and for the creation and maintenance of trust in economic relationships (Leyshon, 1997).

The importance of trust and personal contact is particularly true in the creation of economic clusters and, the so-called, "learning regions" (Wolfe, 2002). Learning regions are generally defined as geographic areas that offer the right mix of environmental ingredients to create social and economic learning among both institutions and workers. In an excellent review of the current state of research regarding learning regions and associated clusters of desirable types of 
companies, Wolfe (2002) argues that, in Europe, more so than in North America, social networks and trust make important contributions to dense intra-firm relationships and interactive learning. These relationships, in turn, create zones or regions where innovation and creativity are supported institutionally and environmentally. ${ }^{1}$

Porter's (1998) work among others, on regional clusters, makes similar claims for the role of trust and social networks in the formation of dynamic and growing economic or business clusters. He defines clusters as a "geographically proximate group of interconnected companies and associated institutions in a particular field, linked by commonalities and complementarities" (1998, p. 199). Networks and relationships and the trust created through regular and positive interactions allow firms to gain competitive advantage and to become an effective cluster of firms that work together to overcome common barriers to success. Porter and others, such as Saxenian (1994) and Storper (1997), also argue that communication and interaction are only possible and effective after there exists a relatively high level of trust among participant firms.

These studies also point to a series of fortuitous circumstances that enabled cluster development, such as the highly decentralized nature of post-secondary education in the United States with complementary yet connected roles for multiple levels of government, and tax changes that ultimately created a positive environment for the growth of venture capital. Ultimately, however, researchers agree that there is a broadly defined set of economic factors (including important cultural practices) that facilitate the creation of learning regions including adaptable skills, suitable physical infrastructure, adequate financing, and an attractive quality of life. The findings from this body of work imply that building trust is a challenging process that requires regular and frequent communication and dialogue between individuals within the different firms, institutions, and agencies involved in the process of economic growth.

\section{Trust and Development in the Developing World}

There is a broad literature exploring community development and social capital within slum communities in the developing world. ${ }^{2}$ Trust and development in this literature stem from several sources, such as shared crises (e.g., eviction, co-optation by government) and consequent self-organization, the overlap of communal action across spheres of activity (e.g., livelihood and

\footnotetext{
${ }^{1}$ Not surprisingly, Wolfe (2002) also argues that a key element underlying social capital of a region is the degree of trust that exists between the groups and members of institutions that it subsumes.

${ }^{2}$ This paper cannot hope to effectively summarize the important work of authors as varied as, for example, Turner (1972, 1976), Laquian (1969), Douglass and Zoghlin (1994), Douglass, Ard-Am, and Kim (2002), Berner (2004), Berner and Phillips (2003), Eckstein (1990), Desai (1995), Bebbington and Perreault (1999), and Beard (2005). We do, however, note some individual contributions that might help shed light on why or how space might influence trust in different slum communities.
} 
employment with environmental improvement), the socio-demographic characteristics and cultural norms of behavior among residents, and governance structures and practices.

Turner (1976) is credited with recognizing the importance of valuing the capacity of slum dwellers to create and shape their built environment and develop their communities. Building on this argument, Eckstein (1990) argues that inner-city slums in Mexico City represent the most hopeful sites for economic opportunities (as compared to suburban slums) because inner-city residents, in addition to shared cultural practices and beliefs, self-organize to a greater extent than residents in the periphery potentially leading to more ability to achieve permanent improvements in the quality of life. The source of such self-organization is the longer term shared living arrangements of the central slums and their successful resistance of government efforts to co-opt the residents both before and after the transformative effects of the 1985 earthquake in Mexico City.

Douglass and Zoghlin (1994) argue that to be sustainable, development must address livelihood and environmental questions simultaneously. They find that low-income households in Bangkok, Thailand devote significant amounts of time and resources to environmental management as part of their livelihood strategies. The capacity for households to engage in improving environmental management is contingent upon particular sets of circumstances, including community stability, land and housing tenure, leadership, and the dedication and commitment of extra-community sources of organization and power.

In a recent paper, Beard (2005) finds that, in Indonesia, a variety of factors influence an individual's willingness to participate in civil society, an issue critically important to social capital and trust. She finds that, in particular, participation is very much related to "socioculturally prescribed family and gender roles" (2005, p. 36). In fact, age, gender, civil status, age of children, and literacy all appear to be important factors in determining if, and to what extent, people decided to participate actively in community affairs. In addition, residents of the main island of Java (which holds a privileged position in Indonesia's economy and political system) in contrast to other more remote islands, are also more likely to exhibit positive social capital as are rural area residents compared to urban dwellers. This work implies then that governance and socio-cultural practices play important roles in participation.

\section{Space, Trust, and Communal Action}

From this research on trust and economic growth, and on community participation among low-income residents in developing countries, we posit the following relationships among space, trust, and communal action. First, the large literature on community development and participation in the developing world suggests that there are spatial dimensions to trust and development. Although much of the literature focuses on the social dimensions of communal 
action, these findings also indicate the specific spatial characteristics of trust. For example, shared crises in low-income communities stemming from eviction, restructuring or oppressive government action clearly have spatial implications as particular enclaves are targeted for clearance and relocation. Immediate need overcomes existing mistrust in those communities where communal action takes place. The socio-cultural and political norm structures of these communities then result in a spatial map of self-organization and mobilization. We can argue that this spatial map of mobilization signifies "communal zones" or spatialized trust where, for those enclaves engaging in communal action, there is positive and regular interaction among community members and between communities leading to the capacity to overcome government edicts or other threats to community survival.

Second, the spatial theories of economic development and firm clustering indicate that such clusters or learning regions are places where creativity and innovation are encouraged, facilitated, and financed. In a similar way, we can posit that communal action and trust in low-income communities in developing countries might be similarly constituted in places. That is, where shared crises have led to effective self-organization, where shared cultural norms or gender roles lead to regular communal activity, and/or where income generating activities address environmental conditions, we argue that places are created where trust and communal action are encouraged, facilitated, and may be financed. Governance (both in terms of government agencies, as well as international donors, community-based NGOs, and community leaders) becomes particularly important in this spatial dimension of trust to finance and build physical infrastructure and to otherwise facilitate the regular social interactions among community members (through meeting sites, transportation, and other in-kind services). In places such as Vietnam, government regulates regular communication among residents, while in Thailand, communications networks may be based more on socio-cultural, familial, and patron-client relations. Maintaining regular and positive communication among urban low-income slum dwellers is very problematic in any context, and consequently, the formation and sustainability of trust is very difficult. The spatial map of trust, or "communal zones," will consequently be influenced by available government or NGO funds and services, stability of community and resident resources, and ability to maintain regular and positive communications networks.

\section{MEASURING TRUST}

Measuring trust is quite problematic, because trust is conceptualized in many different ways, with definitions ranging from the cognitive and experiential to the moral and philosophical. For example, some scholars argue that trust in others is the result of varied personal experiences with family, school, media, workplace, and engagements with other types of institutions (Alesina and La Ferrara, 2000). Others in contrast believe that social trust is formed through individual morality and values (Uslander, 1999; Fukuyama, 2000).

(C) Blackwell Publishing, Inc. 2006. 
Despite some disagreement about the constitution and definition of trust, social scientists have primarily relied on two methods to measure it. One involves relying on surveys while the other uses experimental economic games. Surveys ask respondents directly about how much they trust people in specific social institutions, such as their neighborhood or their government or, the degree to which they participate in communal efforts, for example, did they participate in a recent community-based or volunteer activity?

Recent examples of survey methods to measure trust in international contexts include Freitag (2004), who finds that high levels of confidence in political institutions in countries as dissimilar as Japan and Switzerland provide fertile grounds for social trust. Another is Daniere, Takahashi, and NaRanong (2002) who find in Bangkok, Thailand that increased number of social interactions by community residents is associated with increased community participation because more interactions apparently work to enhance trust. Isham and Käkhönen (2002) find in India and Sri Lanka that community-based water projects are more successful if community members play a key role in implementation. Participation in implementation is associated with higher levels of trust, because such projects tend to focus on community, rather than individual benefits.

There are a number of challenges associated with relying on survey data to estimate or measure trust. Carpenter and Cardenas (2005), among others, note that respondents are likely to be less than truthful regarding their answers to questions about their behavior or their values because they want to present themselves to be more compassionate and socially acceptable than their actual behavior might suggest. Survey researchers have also long pointed to the issue of social bias, in that respondents will tend to answer questions in ways that they believe the surveyors are seeking.

In contrast to survey methods, experimental games measure behavior more directly. Many experimental games are designed so that it is costly and/or more risky to participants to engage in behavior that benefits the group and that can be altered slightly during the course of the game to test for different types of responses as the situation changes (Carpenter and Cardenas, 2005). Examples of recent international research that relies on experimental games methods include Cardenas (2003), Hoff and Pandey (2003), and Carpenter, Daniere, and Takahashi (2004a, 2004b). However, while they all provide important results using this methodology, none of these papers focused on the spatial dimensions of trust.

Cardenas (2003) in villages in Columbia studies the sustainable management of common resources (i.e., local forests). His experiments with Columbian peasants suggest that participants' wealth and inequality of income are negatively associated with cooperation. Hoff and Pandey (2003) within the Uttar Pradesh in India focus on the role of caste in determining the economic performance of individual schoolchildren. Specifically, they test the hypothesis that an historical legacy of discrimination gives rise to expectations of prejudice and mistrust, and find that advertising the caste of a child prior to playing an 
experimental game causes low-cast children to perform half as well as might be predicted if the caste status of a particular child were kept unknown. Carpenter, Daniere, and Takahashi (2004a, 2004b), in metropolitan Bangkok and HCMC, which use the same data as this paper, find very high rates of cooperation among the urban poor in both countries. Furthermore, behavior differs between cities and different variables appear to be correlated with trust behavior in each city. For example, years of schooling are positively associated with higher levels of trust and cooperation in Vietnam but not in Thailand. However, only an aggregate measure of spatial difference, city, was used in the analysis.

\section{CONTEXT}

Our research on trust in Bangkok and HCMC took place over 3 years in five specific communities each in Thailand and Vietnam. ${ }^{3}$ This section provides a brief description of each city to provide context for the results.

\section{Bangkok}

Bangkok is part of an urbanizing area consisting of more than 15 million people with approximately 11 million inhabitants within its metropolitan region (National Statistics Office, 2000). The population has more than doubled since 1984, partially due to growth fueled by manufacturing and, to a lesser extent, the service sector. The Bangkok Metropolitan Region (BMR) attracts migrants from throughout Thailand as well as Burma, Cambodia, and Laos.

While Thailand has experienced increases in GDP and household income for many years (with the exception of the years following the economic crisis in 1997), many individuals in Thailand and Bangkok remain quite poor (Krongkaew and Kakwani, 2003). Such households live in low quality housing and lack access to basic services including water and sanitation, transportation, and health. In the context of a country whose wealth is expanding, social and physical infrastructure investments lag behind what might be expected or predicted (Walter, 2002).

Thailand's relative lack of progress toward addressing housing inadequacies, poor transit, and increasingly visible and harmful levels of pollution lies squarely with the central government (Pasuk and Baker, 1995). The central government operates in a laissez-faire fashion that permits families with

\footnotetext{
${ }^{3}$ The communities that form the basis of this study are recognizable and geographically distinct; they are comprised of relatively poor-quality housing, small lanes or pathways, and a varied history of tenure security, tenure period, size, etc. For more details regarding these communities and how representative they are of low-income neighborhoods in Thailand and Vietnam, please see Tables 1 and 2 and Daniere et al. (2005). While we recognize that the concept of community is problematic, at best, and that communities are both sites of harmony and conflict, we also believe that the neighborhoods selected for the study represent high trust communities, and that they function as important places for residents to organize for political, economic, and social purposes.
} 
connections to the elite to amass fortunes as well as benefit from laws and loopholes to which most Thais do not have access (Shatkin, 2004). ${ }^{4}$

Most Thais believe that their country is becoming more democratic. This is largely the result of three related trends including rapid increases in access to primary education, the growth of an urban middle class and the significant growth of civil society groups devoted to political reform (Pasuk and Baker, 2000). The bureaucracy that governs Thailand is making some progress along a number of dimensions including education, health, and planning. Consequently, in almost all urban communities, the local governments, in particular, are making substantial efforts to increase participation through meetings and discussions; numerous NGOs, similarly, attempt to engage in participatory and community-based action (Missingham, 2002; Tejapira, 2002). While, fundamentally, Thailand remains an unequal country, Bangkok citizens are sometimes able to improve their circumstances through combined efforts to affect change (Daniere, Takahashi, and NaRanong, 2002).

The metropolitan region of Bangkok consists of the central core, the inner suburbs and the outer suburbs, which are comprised primarily of five large provinces (or changwats). Bangkok originally consisted of a governmental complex located on the eastern bank of the Chao Praya River as well as an urbanized area directly across from the historical core, known as Thonburi. As the city grew outward, the financial and tourist sections, clustered primarily around universities and hotels, became the very active areas of the city; consequently, the main tourist/commercial street in Bangkok, Sukhumvit Road, is generally considered the downtown core of the city. While the BMR obviously has many centers of substantial economic activity, most residents would identify the primary center of economic activity in the Sukhumvit area.

The selected communities represent the diversity of locations and living arrangements available to low-income households within Bangkok (Table 1). They differ along several dimensions including geographic location relative to Sukhumvit Road, the size of the communities, the length of time that the community has existed and environmental infrastructure. Communities 1 and 4, for example, are best described as located in the urban core, while Community 2 is located in an inner suburb. Communities 3 and 5, on the other hand, are located in the outer suburbs that, while being part of the metropolitan region, are quite far from downtown Bangkok (Figure 1). Our initial research on the five Bangkok communities revealed that each neighborhood is quite different from the others, particularly in the role and impact of community-based organizations on community environments (Daniere, Takahashi, and NaRanong, 2002). In particular, Communities 1 and 5, and to some extent Community 2,

${ }^{4}$ Fahn (2003) documents a number of examples of political corruption and economic benefits flowing to the elite from environmental exploitation and destruction. For example, logging of tropical lumber along the Burmese border was controlled directly by General Chavalit Yongchaiyudh (Prime Minister of Thailand in the mid-1990s) who parlayed his political power into formidable logging profits. 
TABLE 1: Slum Communities in Bangkok

Community 1: Geographically distinct section of the famous Klong Toey slum located on a huge swath of land surrounding the Port of Thailand. The area has a large number of neighborhood-based NGOs including the Duang Prateep Foundation (founded by a Magsaysay Prize recipient living in the community) working to improve the physical conditions and community residents

Community 2 (Ruam Samakkhi): Located in a newly (last 10 years) urbanized section of inner Bangkok, along a small, very contaminated klong (or canal). The entire community sits about 6 feet above the surface of a canal, a position that is maintained through the use of concrete stilts; brackish water sits below the housing structures, emanating odors into and around dwellings

Community 3 (Trak Tan): Located outside of central Bangkok in the adjoining province of Samut Prakan, but the area around Trak Nan is entirely urban. Most of the land is owned by a variety of entities including a nearby Buddhist temple and private landlords, but wealthy households have begun to build large, impressive homes in the midst of the crowded lanes. Solid waste is a major issue and garbage is everywhere; rats appear to be the most aggressive, problematic form of vermin in this community. This community is the wealthiest slum and has the largest average household size of all five slums

Community 4: Located on the north and south of a major road (soi) running through downtown Bangkok in railway lands. The housing stock is particularly poor in quality, and mostly composed of wood. Standing water and garbage are clearly visible beneath the houses. The community's central location in Bangkok means that the value of real estate is quite high; therefore, the likelihood of eviction seems greater than at the other four locations

Community 5 (Sin Samut/Prachatipat): Located in suburban Pathum Thani province. Residents are dispersed in an almost rural environment along the banks of a large klong full of plants and animals. Within the slum there are at least two distinct areas, differentiated by age and land ownership although both groups are very poor and earn significantly less than households from the other four settlements. The first settlement, which resides upon the land owned by the Irrigation Department, is about 20 years old. The second settlement, existing for around 30 years, occupies land that was recently transferred from a member of the royal family to an insurance company. Both communities are actively being threatened with eviction. Intervention on the part of the Department of the Interior has given slum members the opportunity to purchase property through their savings groups. They are in the process of trying to assemble the required down payment. Unfortunately, there is not enough space to accommodate all the households even if all of the members of both communities were interested in moving there. Specific households - those living on the land owned by the Irrigation Department-have been given the option of moving to other sites owned by the Housing Authority. There is considerable resistance within the community to this second option, because the land is distant, the residents must pay for the land, and they would need to find jobs in the new area, which would likely be difficult to do. In fact, a group has formed to resist attempts to move the community from along the edges of the canal 


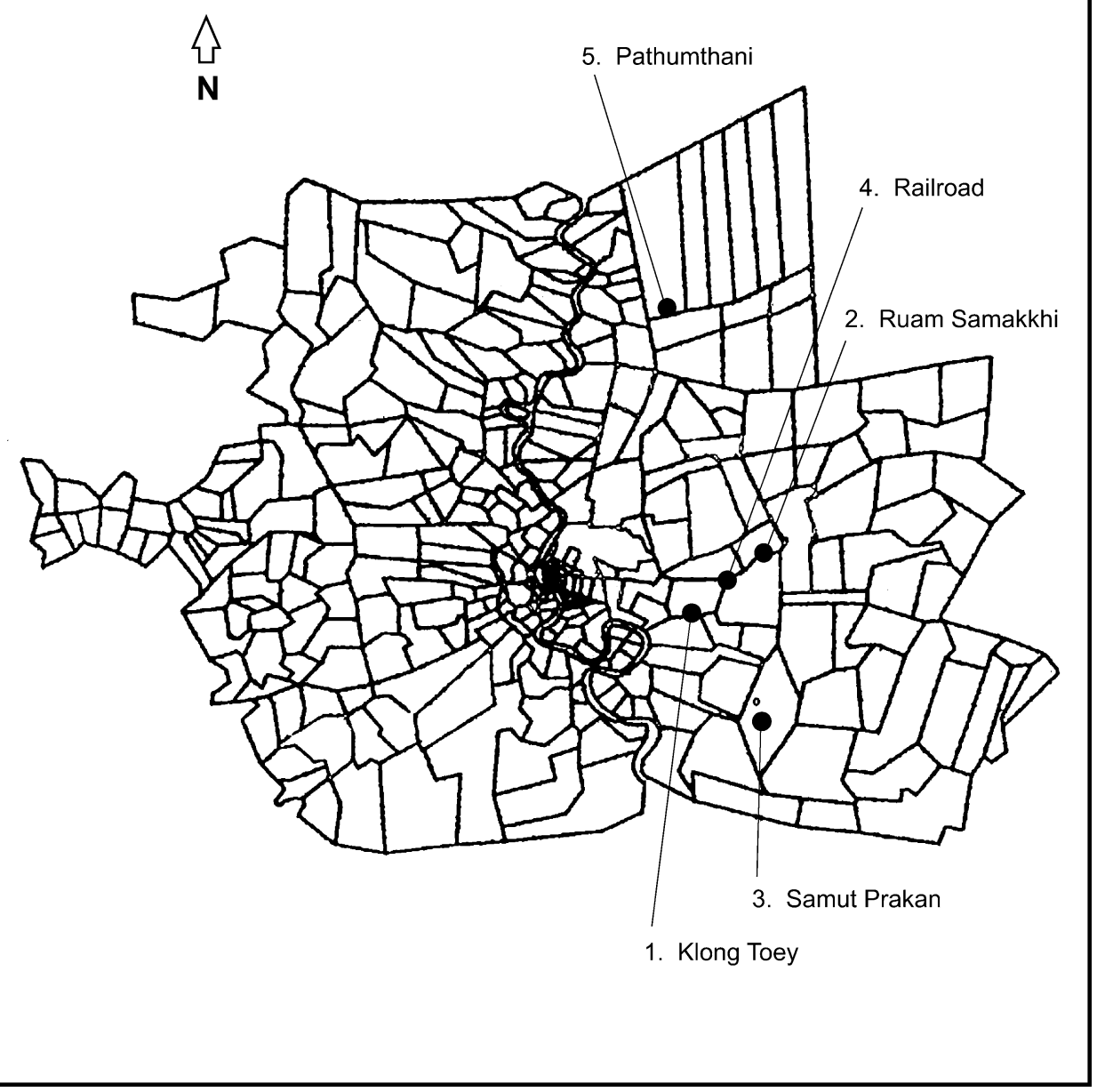

FIGURE 1: Bangkok Community Locations.

have relatively effective community-based organizations that have negotiated improvements or land tenure arrangements on behalf of the residents.

\section{Ho Chi Minh City}

HCMC is also a rapidly growing and expanding urban area that serves as its country's economic engine. The political situation differs in fundamental ways from that in Bangkok, despite the 1986 decision of the Vietnamese Communist Party to launch into a period of economic reform (known as doi moi). As 
it transitions from a centrally planned economy to a socialist market economy, Vietnam has both encouraged and resisted new economic and cultural processes and allied foreign influences (Gainsborough, 2002). One of the Vietnam state's main dilemmas has been how to manage the emergence of market forces within an existing Marxist ideology (Dixon and Kilgour, 2002).

In essence, the Vietnamese government has the competing goals of political control and economic liberalization. On one hand, private investment is facilitated for tangible economic benefits that accrue particularly to certain groups, such as members of the Communist Party, domestic private entrepreneurs, local governments, and international organizations. On the other hand, it seems apparent that at least some Party members fear the rapid pace and broad reach of Vietnam's transition, because it could decrease their political power as well as undermine the socialist values that, even today, define Vietnam's cultural identity.

In terms of the urban administration in Vietnam, it is both highly centralized and yet, at the same time, quite decentralized. The laws and regulations that establish urban policy are the responsibilities of the central government in Hanoi. The national government also provides most of the funds supplied to lower levels of the government charged with implementing these policies. At the regional level, each city and major town has a "People's Council" that functions similarly to U.S. city councils. The councils are responsible for administrating the local government and have some degree of independence concerning urban issues, particularly infrastructure, housing, schools, and environmental protection.

The largest cities contain more than one district. In HCMC, there are a total of 18 districts. Each district has its own People's Committee which, in turn, engages in some autonomous planning and implementation of programs. The Committees can, for example, authorize building permits and have their own funds to implement specific types of infrastructure improvements or buildings. Overlying this structure is the administration of the Communist Party, the only political party in the country, whose presence is felt at every level of government and that provides the unifying principles underlying all policy. Finally, there are the so-called "Mass Movements" such as the Youth Organization and the Women's Union which engage Vietnamese citizens on a more personal level than the Party, but operate through Party support (Coit, 1998).

There has been little opportunity for spontaneous grassroots movements other than those connected to the state or the Party. In the last decade, however, government agencies at all levels have permitted the proliferation of new mass organizations and other less formal organizations/groups to operate. Thus, some observers note significant reductions in the role of the state and the opening up of space for political dissent (Noerlund, 1998; Lloyd, 2003), while others argue that the Communist Party will never permit any form of pluralist democracy (Dixon and Kilgour, 2002). Still others believe that the enormous increase in opportunities for people to come together for social and economic purposes is

(C) Blackwell Publishing, Inc. 2006. 
inevitably causing Vietnam to have a more active and engaged civil society (Van Luong, 2003).

HCMC, like Bangkok, has a historic urban core, but is undergoing a rapid period of metropolization that has had positive results for many (such as increased incomes and a much broader availability of desirable consumer goods), but is accompanied by environmental deterioration and the negative effects on the poorest members of the community (Wust, Bolay, and Du, 2002). Recent surveys suggest that access to basic public services, such as water and sanitation, as well as social services, such as health and education, which are no longer free since the introduction of $d o i \mathrm{moi}$, is inadequate among the poorest households (Beresford, 2001; Wust, Bolay, and Du, 2002). While HCMC has a smaller number of squatters than Bangkok, due not only to policies that penalize rural-urban migration without the permission of the state but also Vietnam's relatively well-funded and executed strategies for re-housing of illegal squatters, there is, nonetheless, a sizable population living in precarious conditions (Coit, 1998). In fact, recent estimates suggest that this population could make up as much as 10 percent of the population of approximately 6 million people living in the metropolitan area (Wust, Bolay, and Du, 2002).

The communities where we conducted our research represent different types and locations (Table 2, Figure 2). Communities A and C, for example, are located relatively close to the colonial center of HCMC, Lam Son Square. These two communities are very urban and dense in character but differ in terms of the quality of their housing, as the buildings in Community A are built of brick or cement and often of more than one storey while Community $\mathrm{C}$ is lined with shacks constructed of wood, plastic, and tin. Community D is also completely urban in nature but is located in the port lands of the city, which often serve to absorb new migrants to HCMC. The infrastructure here is of particular concern. The communities located in the urbanizing areas, Communities B and $\mathrm{E}$, are quite far from Lam Son Square, 20 and $15 \mathrm{~km}$, respectively. However, these areas are rapidly becoming more urban. Public services, nonetheless, are almost nonexistent. Interestingly, because of the widespread reliance on committees and community organization, there are no major differences between the five Vietnamese communities in terms of NGO experience and community organizing. The communities are very similar with respect to experience with cooperation and community organizations.

\section{METHODOLOGY}

This paper uses two sources of data to estimate trust across urban space, i.e., responses to survey questions and results of experimental games. ${ }^{5}$

\footnotetext{
${ }^{5}$ Descriptions of how the communities were selected to participate in the research project and other details regarding our actual methods of conducting the research in the field are available from the authors.
} 
TABLE 2: Slum Communities in Ho Chi Minh City

Community A (Tan Dinh): Located in the central district (ancient Saigon) in a single triangular-shaped city block. The community is close to the Tan Dinh Market, a scene of much economic activity both day and night. Some residents have lived there since prior to the war, but others (mostly recent migrants) live around the market without any permanent dwelling. The housing pattern is extremely dense; a mix of materials including plaster, brick, tile, and cement with the occasional tin roof or siding. Quality of housing structures seems high (many consist of two stories), but conditions are extremely crowded with little floor area available per household. Despite high density, communal alleys and walkways are kept clean and most residents appear to have toilets/septic tanks as well as daily access to garbage collection

Community B (District 2): Bounded on one side by the Saigon River and on the others by rice fields, District 2 was recently re-zoned by the City's People's Committee as urban land. The area remains relatively isolated and rural with no current access by car; work is underway on a highway that cuts through rice fields owned by community members, which will allow quick passage into the city across the river. While most households are very poor rice farmers and own simple wooden homes with roofs made of palm fronds, some community members have sold land near the planned highway and are constructing very large, modern plastered houses. Public services within the community are quite limited, even for the wealthier households. Most houses have piped water and electricity, but there are few indoor toilets and garbage collection is unavailable. The community relies on public outdoor toilets that release waste into swampland; each household has a garbage pit in which to dispose off solid wastes

Community C (District 8): Located on one side of a small island that is formed by the meeting of three canals. Community uses a deteriorated wooden bridge to cross the canal; very poor housing conditions. The structures are predominantly one storey and few improvements have been made to the wooden and corrugated tin exteriors. Community resembles Bangkok, because it is very urban in character, dilapidated in terms of built structures, has narrow pathways, and borders a canal full of garbage. Interesting array of small industries, including an industrial laundry, cottage shoe production, and a small open-air market where merchants sell goods under thatched umbrellas. Little garbage collection

Community D: Situated at the periphery in southwest Ho Chi Minh City in the portlands of the city where many migrants have moved to the city over different time periods. Streets and alleys are extremely old and narrow amid high-density warehouses. Appears homogeneous (primarily two stories high, plaster coated with many shared walls) with little evidence of any new construction. The People's Council suggested this slum because the basic infrastructure of the community is in terrible condition. There are two lively street markets located on either end of the community selling primarily processed and unprocessed foods, some of which are made and sold by women of the community. Many of the men from this community find more or less regular employment in the port or nearby harbor

Community E (Tan Binh): Situated in the northeast area of Ho Chi Minh City-a peripheral zone that until 8 years ago included agricultural land and activities. Most of the residents migrated from rural areas, and constructed their houses upon land that used to be a cemetery. There is great variety in housing styles and quality and differing access to piped water, electricity, and drainage/sewage connections. Two canals flow through this community and, while regularly dredged, are full of garbage and black water. Area is urbanizing very quickly and is rapidly becoming very polluted. The causes of deterioration include construction of dwellings without adequate planning, lack of a drainage system, and the direct disposal of garbage into canals as well as the operation of small-scale industry (especially in terms of dust, smoke, and chemical agents) 


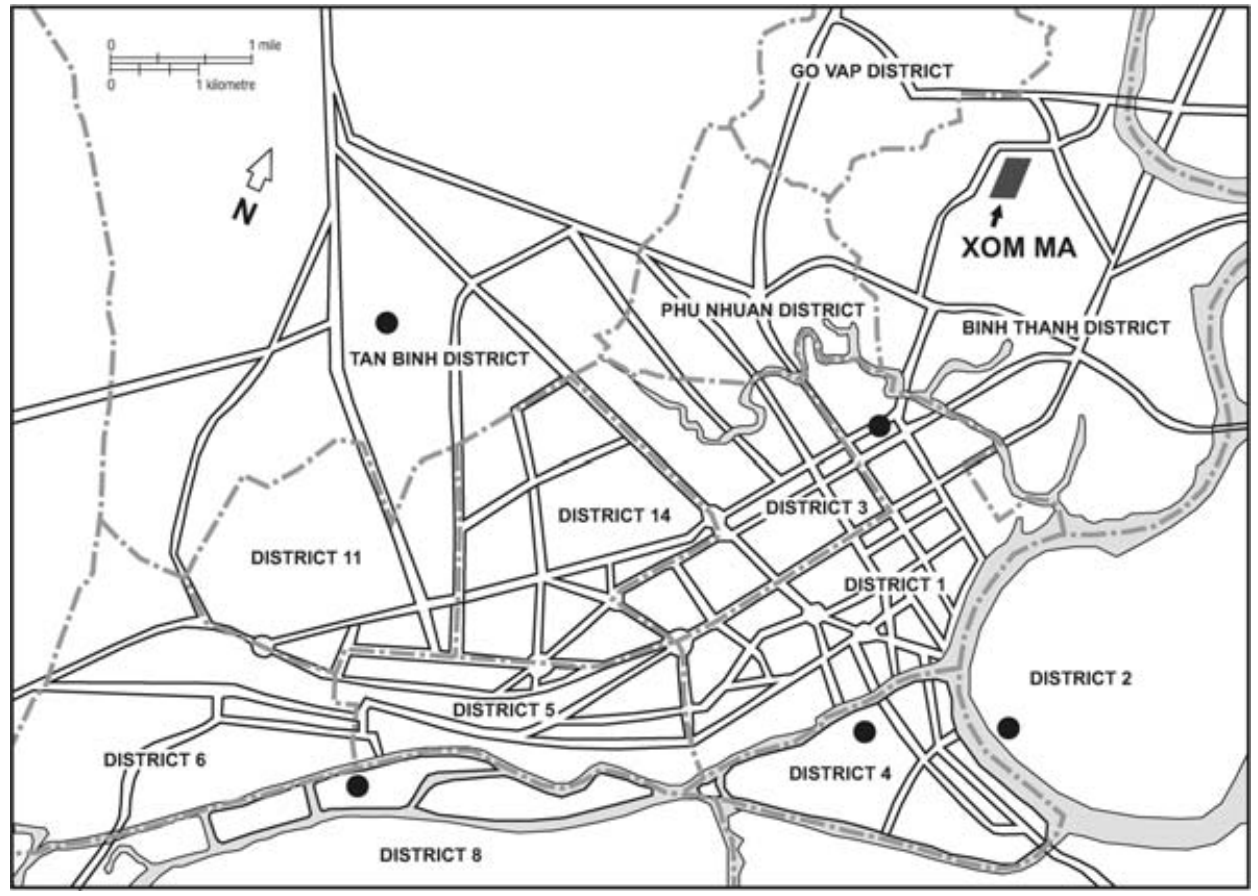

FIGURE 2: Ho Chi Minh City Community Locations.

\section{Household Survey}

The survey data were gathered from a brief questionnaire administered to the participants following the completion of the experimental games. The participants were given an additional payment for staying for the survey interview. The survey included demographic questions as well as questions regarding individual values/norms and environmental behavior. We should note that two of the authors have worked with these same 10 communities since 2000 when we initiated a project that gathered quantitative and qualitative information from numerous households and individuals over the course of 3 years.

\section{Experimental Games}

The experimental games, conducted during the summer of 2002, were designed to model the behavior of people in communities who typically face real social dilemmas, such as the maintenance of clean pathways and sewers. The games are variants of what are known as basic voluntary contribution (Davis and Holt, 1993), which have been played throughout much of the industrialized 
world and, in particular, on North American campuses. ${ }^{6}$ In our version, each person plays 10 rounds consisting of two separate sections, or treatments, of 5 rounds each. Each player is one of a group of four people who play together the entire game. We were able to run the games six separate times within each community, so that, in total, we collected data from 24 players per site. Thus, we compiled responses from 240 people ( 2 cities, 5 sites per city, 24 people per site). Finally, the stakes of the game were set to reflect currency denominations so that if all participants cooperated, they could potentially earn somewhere between a half and a whole week's wages (approximately $\$ 44$ US in Thailand and $\$ 12$ US in Vietnam).

At the beginning of each game, participants were seated at some distance from one another and were asked not to communicate with each other until they had completely finished playing all 10 rounds. Each round began with each player receiving 10 bills or coins (5 Baht coins in Thailand and 1,000 Dong bills in Vietnam). During all rounds, the experimenter sat behind a blind close to the players (this blind was sometimes a chalkboard, a blanket suspended from the ceiling or, in some cases, the experimenter sat outside of the room). Each round, every player would go behind the blind twice to either contribute or receive money. The blinds were designed to permit players to make their decisions privately.

\section{First Section-Voluntary Communication Mechanism (Rounds 1 Through 5)}

On the first trip behind the blind, participants decided how many of the 10 bills (or coins) to allocate to a common cause (or public good) and how many to keep for themselves. Once every player had been behind the blind for the first time, the experimenter counted and doubled the sum of all the contributions. Each person then returned behind the blind to receive an equal share of the doubled amount. At that time, each player would see a listing of the different contributions of each of the four players (including themselves) but were not told which player contributed which amount. This technique provides the incentives of a social dilemma, because individuals can always do better by free riding off the contributions of the other group members. ${ }^{7}$

${ }^{6} \mathrm{~A}$ similar but more complete discussion of the experimental games can be found in Carpenter, Daniere, and Takahashi (2004a) on pages 860-862. We thank Taylor and Francis Publishers (http://www.tandf.co.uk) for their permission to substantially reproduce the description of experimental games here. In addition, see Ledyard (1995) for a survey of the results from industrialized countries in the voluntary contribution mechanism, and Cardenas and Carpenter (2005) for a review of behavior in the developing world. The instructions to participants are available from the authors upon request.

${ }^{7}$ The payoff function for each player is: $\left(\left(10+x_{j}\right)+\left(2 \sum x_{j} / 4\right)\right)$, where $x_{j}$ is individual $j$ 's contribution to the public good (and a behavioral measure of the propensity to cooperate in a social dilemma). This is a social dilemma because putting any money in the public good returns only half that amount to the participant; this means free riding is the dominant strategy. But, if all participants allocate everything, they each receive 20 back, which is larger than the 10 they receive if each participant keeps it all; so contributing is socially efficient. 
Second Section-Social Sanctioning (Rounds 6 Through 10)

At the end of round 5, we changed the rules to add the following, simple social sanctioning mechanism. It is important that we did not tell our participants that we would change the rules between rounds 5 and 6 , because we did not want them to condition their early play on the future rule changes. We told the participants that for one-fifth (20 percent) of a bill or coin (i.e., 1 Baht or 200 Dong), any participant could have a picture of a frowning face (2) displayed at the beginning of the next round. In the instructions, we said that the picture is meant to express one's dissatisfaction with the contribution choices of one or more of the participants in the group. In this case, while it is costly to show disapproval, any benefit of the sanctioning must be due to social pressure because the sanction has no material fine attached to it. The social sanctioning game began each period, as in the previous five rounds, with an endowment of 10 bills (or coins) and on the first trip behind the blind, each participant faced the same two choices-to allocate some or all of the money to the public good or to keep it all. The only difference occurred on the second trip behind the blind, when the participant was informed how much the other participants contributed and picked up her earnings from the public good. At that point, each participant could elect to pay one-fifth of a bill or coin to visually sanction the rest of the group at the start of the next round. We were interested in noting the number of times that a participant was willing to pay to show dissatisfaction as economists use this to measure the propensity to punish others, which can be considered an element of trust and cooperation.

\section{RESULTS}

To examine spatial dimensions of trust and cooperation in our data from Southeast Asia, we regressed experimental behavior on demographic controls and two constructed variables designed to account for: (1) the distance between the community in which the experiment was conducted and the city center and (2) whether the communities are best categorized as urban or suburban. These variables and their values are reported for each community in Table 3. The demographic variables that we control for in the analysis overlap with those in Carpenter, Daniere, and Takahashi (2004b) and include the gender of the decision-maker (Female), the number of years of schooling the decisionmaker had completed (Schooling), the participant's age (Age), the number of people in the participant's household (Household), the number of years that the participant had lived in the slum (Residence), and the participant's score on a cooperative personality scale (Cooperation Scale).

The cooperation scale is based on six statements that respondents either agreed with, disagreed with, or to which they gave no response. ${ }^{8}$ We included

\footnotetext{
${ }^{8}$ The statements were: "Cooperation is better than competition (+)"; "People should listen to their conscience when making decisions (+)"; "People should forgive others easily when angry 
TABLE 3: Community Location

\begin{tabular}{lcl}
\hline \hline & $\begin{array}{c}\text { Distance from } \\
\text { center }(\mathrm{km})\end{array}$ & \multicolumn{1}{|}{$\begin{array}{l}\text { Urban/ } \\
\text { Suburban }\end{array}$} \\
\hline Bangkok & & \\
Community 1 & 4 & Urban \\
Community 2 & 6 & Urban \\
Community 3 & 20 & Suburban \\
Community 4 & 5.5 & Urban \\
Community 5 & 25 & Suburban \\
Ho Chi Minh City & & \\
Community A & 3 & Urban \\
Community B & 15 & Suburban \\
Community C & 8 & Urban \\
Community D & 4 & Suburban \\
Community E & 10 & \\
\hline
\end{tabular}

the cooperation scale in the survey to control for cooperative predispositions (and to see if there is a relationship between surveyed measures of cooperation and behavioral measures).

We consider the fact that participants' contribution choices are bound from below by 0 and from above by 10, by using the Tobit estimator which accounts, in the point estimates, for the probability that behavior exceeds either threshold. However, the coefficients that we report are the marginal effects conditional on the dependent variable being uncensored. In addition, because our experiment generates a panel of data (i.e., a repeated cross-section), we account for individual-specific behavior by adding random effects (i.e., individual-specific error terms) to the basic regression model. As it turns out, the random effects are important because they explain no less than 53 percent of the variation in contribution behavior (i.e., the value of $r h o$ in Table 4).

We begin with our Thai data in columns (1)-(3) of Table 4 . In column (1), we regress the amount each player contributes in a given round on the demographic control variables alone. ${ }^{9}$ We see that women in the Thai slums contribute significantly less than men (1.71 coins on an average), additional years of schooling reduce contributions by 0.11 coins, older people contribute less $(0.07$ coins per year), and cooperativeness declines the longer one lives in the slum ( 0.04 coins per year). It does not appear that the size of one's household affects contributions and there does not seem to be a strong link between our measure of cooperation and behavior in Thailand.

with them (+)"; "It is amusing to play tricks on other people (-)"; "People should revenge wrongs done to them (-)"; "Confrontations should be avoided (+)"; where the positive and negative signs indicate whether agreeing increases or decreases one's score by one point.

${ }^{9} \mathrm{We}$ also tried regressing whether or not participants showed disapproval of the group contribution on the spatial variables but found no interesting results. 
TABLE 4: The Demographic and Spatial Determinants of Trust

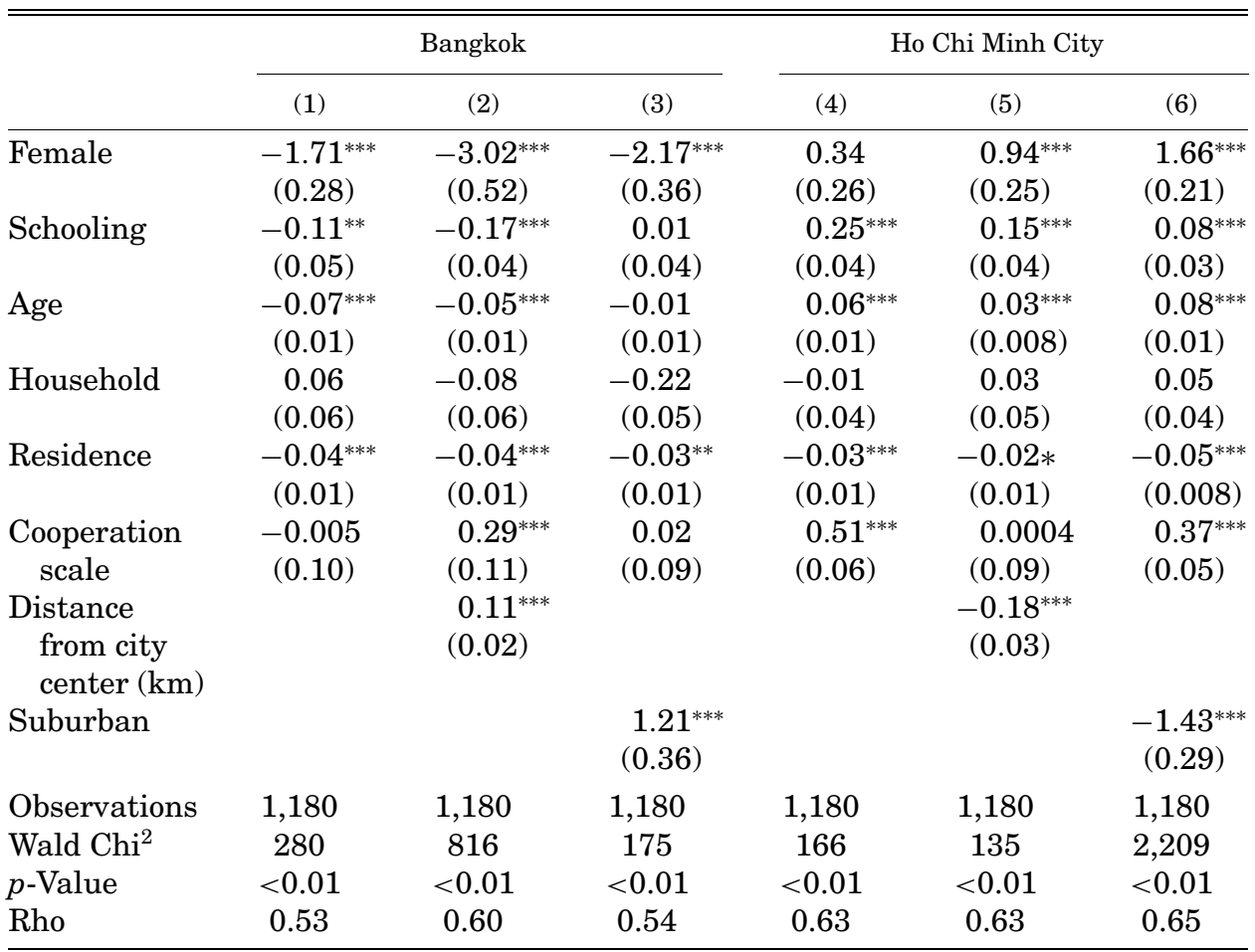

Note: All results include individual random effects. Because contributions are bound from above by 10 and from below by 0 , we use the Tobit estimator. Rho is the fraction of the variation in the dependent variable that is explained by the individual random effects.

${ }^{* * *}$ indicates significance at the 1 percent, ${ }^{* *}$ at the 5 percent, and ${ }^{*}$ at the 10 percent levels.

In column (2), we add the distance (in $\mathrm{km}$ ) between the center of Bangkok and the community. While most of the demographic point estimates change little, the female indicator coefficient increases by more than half. Based on this estimate, women contribute approximately three coins less than men. We also see that including the kilometers variable dramatically increases the magnitude of the cooperation scale coefficient. Furthermore, when we control for the distance from the city center, those participants with higher cooperation scores contribute more in the experiment.

More importantly, however, there is a highly significant association between the distance from the city center and cooperation. For each kilometer traveled from the city center, contributions increase by 0.11 coins. This implies that contributions in Community 3 (Trak Tan) and in Community 5 (Pathum Thani) are 2.2 and 2.75 coins higher than those in the center, respectively.

While it is a coarser measure, the suburban indicator variable also does not impose the linear functional form of the kilometers from the center variable and therefore it may capture more qualitative differences in contributions. In 
column (3), we see that suburban participants in Bangkok contribute 1.21 coins more than their urban counterparts and this estimate is highly significant $(p<$ 0.01). It is also interesting that adding the suburban variable reduces the size and significance of many of the demographic variables. This suggests that part of the variation previously attributed to gender, schooling, age, years of residence, and the cooperation scale are now associated with qualitative differences in the urban and suburban communities. Indeed, in an unreported regression, we interacted the suburban indicator with the demographic variables (e.g., suburban $\times$ female) and found significant differential effects of being female $(-)$, years of residence $(+)$, and the cooperation scale (-) on cooperation. These interactions support the idea that the life in the suburban slums is qualitatively different.

In sum, columns (2) and (3) suggest that there is a spatial element to cooperation in Bangkok. Specifically, people living in suburban slums in Thailand are more cooperative than those who live in urban slums this difference is associated with living in the suburbs, with being a woman, with the duration of one's stay in the community, and with one's cooperative predisposition.

We turn our attention to HCMC in columns (4)-(6). As in column (1), in column (4) we look only at the demographic determinants of contributions. Column (4) suggests that there is no difference in contributions between men and women in HCMC. At the same time, schooling is positively associated with cooperation (perhaps an advantageous vestige of communist propaganda in the curriculum), older Vietnamese are more cooperative, cooperation declines with the duration of one's residence in the slum, and there is a link between surveyed cooperative predispositions and behavior in the experiment. Specifically, one more year of school is associated with a 0.25 bill increase in contributions, an additional year of age is associated with a modest 0.06 bill increase in contributions, another year in the community is associated with a 0.03 bill reduction in contributions, and scoring one point higher on the cooperation scale is associated with a 0.51 bill increase in contributions.

In column (5), we add the distance from each community to the center of HCMC. The first noticeable change in our estimate of the determinants of cooperation is that women are now estimated to contribute 0.94 bills more than men $(p<0.01)$. Furthermore, the distance measure soaks up some of the variation previously attributed to the cooperation scale. However, with respect to location, we find that communities farther away from the center of HCMC are significantly less cooperative. Each kilometer traveled reduces the level of cooperation by 0.18 bills.

Column (6) appears to be a convex combination of columns (4) and (5). On one hand, the point estimate for females is even higher (1.66) than in column (5) but, on the other hand, the cooperation scale is similar in magnitude and significance to that in column (4). The important finding, however, is that the two measures of spatial dispersion support one another. The indicator variable in column (6) suggests that contributions are 1.43 bills lower in the suburbs. 
Not only have we found evidence suggesting that the spatial dispersion of communities affects the level of norms of cooperation and trust in those communities, but have also found that the relationships between a community's proximity to the center of the city and cooperation are exactly opposite in the two locations. In Bangkok, cooperation increases as one gets farther away from the city center, but in HCMC cooperation declines as one moves out from the center of town. To test whether these differences are significant, we stacked the data from the two cites and generated interactions between location and all the right-hand-side variables. If the coefficients on these interactions are significant, then the coefficients differ by location. It should come as no surprise, but the differential effects of distance from the city center and whether or not the community is in the suburbs are highly significant $(p<0.01)$, indicating that the relationships are substantially different in these two cities.

\section{SUMMARY AND CONCLUSIONS}

There are a number of potential compelling explanations for the differences we find in the relationship between trust, cooperation, and location in Bangkok and HCMC. All these lead to the conclusion that trust has important spatial dimensions, and in this case, that differences emanate from the distinctions between suburban and urban communities in the two cities.

In the case of Bangkok, although the two suburban slums are very different (e.g., Community 5 has the lowest household income and Community 3 has the highest household income of all five Bangkok communities that we surveyed), it is important to note that Communities 3 and 5 are both located on land or space that was very public in nature prior to its settlement, i.e., the land settled upon by squatters was so-called "royal" land or land associated/owned by state enterprises that had owned the land for years and, generally, kept it vacant. Once squatters arrived there, they had to deal almost constantly with issues of eviction and establishing legal tenure as they tried to negotiate with these state entities to purchase the land and regularize their tenure situation. The state entities, in these cases and in many other suburban situations, had a very strong position vis-à-vis the new settlers, given their status within the government and the fact that the land was generally undeveloped. The experience of negotiating as a group in a highly tense and critical situation to preserve their housing status may well have created more immediate trust within these communities. This trust and the networks that developed from this crucible of social action are likely ones that endure over time since, as our household surveys revealed, residents of slums in Bangkok are stable, do not move around a lot, and therefore likely have a collective memory.

Another aspect of the suburban slums worth considering is that physical dimensions of these slums are somewhat small, compared to, say, the Railway slum and Klong Toey (which are both enormous in scope as well as being very urban in location), suggesting a smaller number of residents, and a possible 
limitation to mobilization (i.e., lacking a critical mass of residents for effective organizing or mobilizing for public services).

Furthermore, transport linkages that connect the suburban slums to the rest of the BMR are an important factor. Travel to and from the suburban slums is an issue in that daily needs and activities, including employment, are not located within the slum or within easy commuting distance to these slums. In other words, frequent and positive social interactions, and therefore trust, are made more problematic by the challenges faced in creating relationships with persons or groups outside of the slum because of the physical distance between these suburban slums and other slums in the region. Thus, relationships are somewhat more limited to community residents in contrast to relationships outside of the slum.

These factors may well explain why suburban slums are more cooperative than urban slums. The two suburban slums share a common history of having to organize against eviction against a very strong public entity, experience similar challenges in terms of transportation, and are relatively small when compared to urban slums. Urban slums in Bangkok in contrast are larger, more connected to the employment/transportation fabric of the city, and while also illegal in tenure, have long very structured histories of interaction regarding their right to live in these areas. Right of occupancy is to some extent somewhat less of an issue in the slums in our study because both Klong Toey (originally owned by the Port of Thailand) and the Railway slum (located on Thai Railways land) have existed for a long period and government institutions are experienced in dealing with the inhabitants. The final urban slum, Community 2 , is located in limited space contained within a number of modern developments and has excellent connections to the rest of the city. There is a well-organized community group, but these slum residents have not had to deal explicitly with survival, as of yet, but have focused their community efforts primarily on dealing with improving access to basic services such as clean water, a new footbridge, etc.

Conversely, in HCMC, the urban slums have longer and more substantive histories of working together over time to develop and improve their environments and quality of life. Though the urban wards are more crowded than in the past, with new rural migrants that have rented rooms from existing households or moved in with their relatives, in essence, these communities have been home to the same families for many years (at least since 1975 or so). A majority of the households have a right to live on the land in some fashion and have worked together for the last four decades. Ward households know one another very well because of the political structure of the Vietnam, which is administered through local leadership that implements the regulations, good and bad, at a household level requiring regular social interaction.

In the suburban slums of HCMC, however, we see relatively recent migrants who have found places to live that have rarely been used for urban living before the recent opening up of the country to migration and trade. The administration of these wards is still impressive, given how new and poor the communities are, but it makes sense that suburban community members know each

(C) Blackwell Publishing, Inc. 2006. 
other somewhat less well and have less overtly cooperative relationships than the majority of residents in urban slums. In fact, one might normally expect some distrust among households in HCMC suburban communities, given the possible negative repercussions associated with illegal dwelling in the past in Vietnam and the relative control of the Communist Party previously over the location of new households.

This paper and its analysis suggest that space and location are important in understanding trust and communal action within communities in developing countries. This analysis has indicated that space and location are not simply or directly linked to specific levels of trust within slums in rapidly developing regions, but instead, suggests that space matters in different ways given culture, history, politics, and economics of a particular city or country. This variation in the way that space matters points to a critical need for additional research to understand the regional quality of trust, the ways in which urban development patterns enhance or minimize trust, and how such information and knowledge can best be leveraged to improve environmental conditions and environmental policies and practices.

The research question we laid out at the outset points to areas that should be studied further to clarify the relationship between space and trust. First, though our analysis indicated that the spatial/locational characteristics that best explain variations in trust are unique to each city, that begs the larger question of how space influences the building and maintenance of trust, and how governance might facilitate/impede the formation and sustainability of "communal zones." Second, though we focused on the differences in trust between slums closer and farther from the city center, this is a crude measure of development patterns and the spatial character of trust. How then do development patterns affect the ways that trust is developed and used for environmental and other communal social action? Finally, while we assert from this analysis that geography and spatial location are indeed critical to explaining variations in trust and the potential for communal action, much more careful and detailed work is needed to ascertain the particular nature of this relationship among space, trust, and social action. As planners, geographers, and regional scientists begin to clarify this broader relationship, such work can be used to inform policies that take into account not only the particular social context of environmental decision-making, but the spatial context as well.

\section{REFERENCES}

Alesina, Alberto, and Eliana La Ferrara. 2000. "Participation in Heterogeneous Communities," Quarterly Journal of Economics, 115, 847-904.

Amin, Ash, and Nigel Thrift. 1995. "Institutional Issues for the European Regions: From Markets and Plans to Socioeconomics and Powers of Association," Economy and Society, 24, 41-66.

Beard, Victoria. 2005. "Individual Determinants of Participation in Community Development in Indonesia," Environment and Planning C, 23, 21-39.

Bebbington, Anthony, and Thomas Perreault. 1999. "Social Capital, Development, and Access to Resources in Highland Ecuador,” Economic Geography, 75, 395-418. 
Berner, Erhard. 2004. "Legalizing Squatters, Excluding the Poorest: Urban Land Transfer Programs in the Philippines," Working Paper No. 257, University of Bielefeld, Faculty of Sociology, Federal Republic of Germany.

Berner, Erhard, and Benedict Phillips. 2003. "Left to Their Own Devices? Community Self-Help Between Alternative Development and Neoliberalism," Paper presented at the N-AERUS Annual Seminar, Paris, May.

Beresford, Melanie. 2001. "Vietnam: The Transition from Central Planning" (revised) in Garry Rodan and Richard Robinson (eds.), The Political Economy of Southeast Asia: Conflicts,Crises, and Change. Melbourne, Oxford and New York: Oxford University Press, pp. 206-232.

Cardenas, Juan-Camilo. 2003. "Real Wealth and Experimental Cooperation: Experiments in the Field Lab," Journal of Development Economics, 70, 263-289.

Cardenas, Juan-Camilo, and Jeffrey Carpenter. 2005. "Experiments and Economic Development: Lessons from Field Labs in the Developing World," Department of Economics Working Paper, Middlebury College.

Carpenter, Jeffrey, and Juan-Camilo Cardenas. 2005. "Three Themes on Field Experiments and Economic Development," in Jeffrey Carpenter, John List, and Glenn Harrison (eds.), Field Experiments in Economics, Volume 10. Research in Experimental Economics. Greenwich and London: JAI Press, pp. 71-124

Carpenter, Jeffrey, Amrita Daniere, and Lois M. Takahashi. 2004a. "Social Capital and Trust in Southeast Asian Cities," Urban Studies, 41, 853-874.

2004b. "Cooperation, Trust and Social Capital in Southeast Asian Urban Slums," Journal of Economic Behavior and Organization, 55, 533-551.

Coit, Katharine. 1998. "Housing Policy and Slum Upgrading in Ho-Chi-Minh City," Habitat International, 22, 273-280.

Daniere, Amrita, Lois M. Takahashi, and Anchana NaRanong. 2002. "Social Capital, Networks and Community Environments in Bangkok, Thailand," Growth and Change, 47, 453-484.

Daniere, Amrita, Lois M. Takahashi, Anchana NaRanong, and Van Thi Ngoc Lan. 2005. "Social Capital, and Urban Environment in Southeast Asia: Lessons from Settlements in Bangkok and Ho Chi Minh," International Development Planning Review, 27, 21-58.

Davis, Douglas, and Charles Holt. 1993. Experimental Economics. Princeton: Princeton University.

Desai, Vandana. 1995. Community Participation and Slum Housing. Thousand Oaks, California: Sage Publications.

Dixon, Chris, and Andrea Kilgour. 2002. "State, Capital, and Resistance to Globalization in the Vietnamese Transitional Economy," Environment and Planning A, 34, 599-618.

Douglass, Michael, Orathai Ard-Am, and Kim Ik Ki. 2002. "Urban Poverty and the Environment: Social Capital and State-Community Synergy in Seoul and Bangkok," in P. Evans (ed.), Livable Cities? The Politics of Urban Livelihood and Sustainability. Berkeley: University of California Press, pp. 29-61.

Douglass, Michael, and M. Zoghlin. 1994. "Sustaining Cities at the Grassroots: Livelihood, Environment and Social Networks in Suan Phlu, Bangkok," Third World Planning Review, 16, 171-199.

Eckstein, Susan. 1990. "Urbanization Revisited: Inner-City Slum of Hope and Squatter Settlement of Despair," World Development, 18(2), 165-181.

Fahn, James. 2003. A Land on Fire: The Environmental Consequences of the Southeast Asian Boom. Boulder, CO: Westview Press.

Freitag, Marcus. 2004. "Social Capital in (Dis)Similar Democracies: The Development of Generalized Trust in Japan and Switzerland," Comparative Political Studies, 36, 936-966.

Fukuyama, Francis. 2000. The Great Disruption: Human Nature and the Reconstitution of Social Order. New York: Free Press.

Gainsborough, Martin. 2002. "Understanding Communist Transition: Property Rights in Ho Chi Minh City in the Late 1990s," Post-Communist Economies, 14, 227-243.

Gambetta, Diego. 1988. "Can We Trust Trust?" in Diego Gambetta (ed.), Trust. Oxford: Oxford University Press, pp. 213-237. 
Glaeser, Edward, David Laibson, Jose A. Scheinkman, and Christine L. Soutter. 2000. "Measuring Trust," Quarterly Journal of Economics, 65, 811-846.

Hoff, Karla, and Prianka Pandey. 2003. "Why Are Social Inequalities So Durable: An Experimental Test of the Effect of Indian Caste on Performance," World Bank Working Paper.

Isham, John, and Satu Käkhönen. 2002. "Institutional Determinants of the Impact of CommunityBased Water Projects: Evidence from Sri Lanka and India," Economic Development and Cultural Change, 50, 667-692.

Kawachi, Ichiro, Bruce Kennedy, and Kimberly Lochner. 1997. "Long Live Community: Social Capital as Public Health," The American Prospect, 35, 56-61.

Krongkaew, Medhi, and Nanak Kakwani. 2003. "The Growth-Equity Trade-Off in Modern Economic Development: The Case of Thailand," Journal of Asian Economics, 14(5), 735757.

Laquian, Aprodicio A. 1969. Slums Are for People. Manila: University of the Philippines.

Ledyard, John. 1995. "Public Goods: A Survey of Experimental Research," in Johan Kagel and Alvin Roth (eds.), The Handbook of Experimental Economics. Princeton: Princeton University Press, pp. 111-194.

Leyshon, Andrew. 1997. "Introduction: True Stories? Global Dreams, Global Nightmares and Writing Globalization,” in R. Lee and J. Wills (eds.), Geographies of Economies. London: Arnold, pp. 133-146.

Lloyd, Kate. 2003. "Contesting Control in Transitional Vietnam: The Development and Regulation of Traveler Cafés in Hanoi and Ho Chi Minh City,” Tourism Geographies, 5(3), 350-336.

Luong, Hy Van. 2003. Postwar Vietnam: The Dynamics of a Transforming Society. Boulder: Roman and Littlefield.

Missingham, Bruce. 2002. "The Village of the Poor Confronts the State: A Geography of Protest in the Assembly of the Poor," Urban Studies, 39(9), 1647-1663.

National Statistics Office. 2000. The 2000 Population and Housing Census. Bangkok: Office of the Prime Minister.

Noerlund, I. 1998. "The Labour Market in Vietnam: Between State Incorporation and Autonomy," in J. Dragsbaek Schmidt, J. Hersh, and N. Fold (eds.), Social Change in Southeast Asia. London: Longman, pp. 155-182.

Pasuk, P., and C. Baker. 1995. Thailand: Economy and Politics. Kuala Lumpur: Oxford University Press.

—. 2000. Thailand's Crisis. Chiang Mai: Silkworm Books.

Porter, Michael E. 1998. "Clusters and Competition: New Agendas for Companies, Governments and Institutions," in On Competition. Cambridge, MA: Harvard Business Review Books, pp. 197-287.

Paldam, Martin. 2000. "Social Capital: One or Many? Definition and Measurement," Journal of Economic Surveys, 14(5), 629-653.

Putnam, Robert. 1995. "Bowling Alone: America's Declining Social Capital," Journal of Democracy, $6,65-78$.

Saxenian, Annalee. 1994. Regional Advantage: Culture and Competition in Silicon Valley and Route 128. Cambridge, MA: Harvard University Press.

Shatkin, Gavin. 2004. "Globalization and Local Leadership: Growth, Power and Politics in Thailand's Eastern Seaboard," International Journal of Urban and Regional Research, 28(1), 1124.

Storper, Michael. 1997. The Regional World: Territorial Development in a Global Economy. New York and London: The Guilford Press.

Tejapira, K. 2002. "Post-crisis Economic Impasse and Political Recovery in Thailand: The Resurgence of Economic Nationalism," Critical Asian Studies, 34(3), 323-356.

The Economist. 2003. “A Question of Trust," Feb 22, 2003, vol. 366, Iss. 8312, p. 92.

Thrift, Nigel, and Kris Olds. 1996. "Refiguring the Economic in Economic Geography," Progress in Human Geography, 20(3), 311-337. 
Turner, John F. C. 1972. "Housing as a Verb," in John F. C. Turner and R. Fichter (eds.), Freedom to Build. New York: Macmillan, pp. 148-175.

. 1976. Housing by People. London: Marion Boyars.

Uslander, Eric M. 1999. "Morality Plays: Social Capital and Moral Behavior in Anglo-American Democracies," in Jan van Deth, Marco Marafi, Kenneth Newton, and Paul Whiteley (eds.), Social Capital and European Democracy. London: Routledge, pp. 213-239.

Walter, Pierre. 2002. "Adult Literacy Education and Development in Thailand: An Historical Analysis of Policies and Programmes from the 1930s to the Present," International Journal of Lifelong Education, 21(2), 79-98.

Whiteley, Paul. 2000. "Economic Growth and Social Capital," Political Studies, 48, 443-466.

Willinger, Marc, et al. 2003. "A Comparison of Trust and Reciprocity Between France and Germany: Experimental Investigation Based on the Investment Game," Journal of Economic Psychology, 24(4), 447-466.

Wolfe, David A. 2002. "Social Capital and Cluster Development in Learning Regions," in J. Adam Holbrook and David A. Wolfe (eds.), Knowledge, Clusters and Learning Regions. Kingston: School of Policy Studies, Queen's University, pp. 53-87.

Wust, Sébastien, Jean-Claude Bolay, and Thai Thi Ngoc Du. 2002. "Metropolization and the Ecological Crisis: Precarious Settlements in Ho Chi Minh City, Vietnam," Environment \& Urbanization, 14(2), 211-224. 